\title{
O ensino em tempos de isolamento social: percepção de docentes de um curso de formação de professores
}

\author{
Teaching in times of social isolation: perception of teachers of a \\ teacher training course
}

\section{Enseñanza en tiempos de aislamiento social: percepción de profesores de un curso de formación de profesores}

\author{
Jones Baroni Ferreira de Menezes' \\ https://orcid.org/0000-0002-9193-3994 \\ Francisco Nunes de Sousa Moura² \\ https://orcid.org/0000-0002-8745-5010
}

\begin{abstract}
Resumo: Esta investigação objetiva compreender, sob a ótica de docentes vinculados a um curso de formação de professores, o desenrolar das atividades letivas através do ensino remoto. Deste modo, a pesquisa caracterizase como um estudo de caso exploratório, descritivo, de abordagem qualitativa, tendo docentes de um curso de licenciatura em Ciências Biológicas como participantes. Os dados foram coletados através de um questionário on-line e analisados de modo descritivo, categorizados e interpretados conforme preconizado por Bardin (20II). Os participantes elencaram a diversidade de recursos didáticos, flexibilidade de tempo e espaço das aulas como benefícios do ensino remoto, contudo, a inabilidade do uso dos recursos tecnológicos, a falta de apoio institucional, as dificuldades de acesso a equipamentos e a internet prejudicam a efetividade desta prática educativa. Deste modo, os docentes reconhecem a importância das tecnologias educacionais, todavia alertam para as adversidades que podem ampliar a desigualdade de acesso ao ensino, singularmente neste período de distanciamento social.
\end{abstract}

Palavras-chave: Educação. Educação superior. Tecnologias educacionais.

\begin{abstract}
This investigation aims to understand, from the perspective of teachers linked to a teacher training course, the development of teaching activities through remote teaching. In this way, the research is characterized as an exploratory, descriptive case study with a qualitative approach, with teachers from a Biological Sciences degree course as participants. The data were collected through an online questionnaire and analyzed in a descriptive way, categorized and interpreted as recommended by Bardin (20lI). The participants listed the diversity of didactic resources, flexibility of time and space of classes as benefits of remote teaching, however, the inability to use technological resources, the lack of institutional support, the difficulties in accessing equipment
\end{abstract}

\footnotetext{
' Doutorando em Educação (PPGE/UECE). Docente da Faculdade de Educação de Crateús/Universidade Estadual do Ceará. E-mail: jones.baroni@uece.br

${ }^{2}$ Doutorando em Educação (PPGE/UFC). E-mail: nunes.moura@alu.ufc.br
}

Olhar de professor, Ponta Grossa, v. 24, p. I-10, e-15836.046, 2021.

Disponível em <https://revistas2.uepg.br/index.php/olhardeprofessor> 
and the internet hamper effectiveness of this educational practice. In this way, teachers recognize the importance of educational technologies, however they are alert to the adversities that can increase inequality of access to education, particularly in this period of social distance.

Keywords: Education. College education. Educational technologies

Resumen: Esta investigación tiene como objetivo compreender la perspectiva de los docentes vinculados a un curso de formación docente, el desarrollo de actividades docentes a través de la enseñanza remota. De esta manera, la investigación se caracteriza como un estudio de caso exploratorio, descriptivo, con un enfoque cualitativo, con profesores de un curso de licenciatura en Ciencias Biológicas como participantes. Los datos fueron recolectados a través de un cuestionario en línea y analizados de manera descriptiva, categorizados e interpretados según lo recomendado por Bardin (20ll). Los participantes enumeraron la diversidad de los recursos didácticos, la flexibilidad del tiempo y el espacio de clases como beneficios de la enseñanza remota, sin embargo, la incapacidad para utilizar los recursos tecnológicos, la falta de apoyo institucional, las dificultades para acceder a los equipos y la eficacia de Internet obstaculizan de esta práctica educativa. De esta manera, los maestros reconocen la importancia de las tecnologías educativas, sin embargo, están alertas a las adversidades que pueden aumentar la desigualdad en el acceso a la educación, particularmente en este período de distancia social.

Palabras-clave: Educación. Educación universitária. Tecnologías educativas.

\section{Introdução}

O mundo em 2020 iniciou tendo que combater um inimigo invisível, o SARS-CoV-2, conhecido como o novo coronavírus, causador da COVID-19. Este vírus possui uma alta taxa de transmissibilidade na população, além de uma alta capacidade mutacional, se alastrando por todos os continentes mundiais (KHAN et al., 2020). Tal doença causa graves problemas respiratórios, podendo também haver prejuízos no sistema cardiovascular e renal, agravando o caso dos pacientes contaminados (PUELLES et al., 2020).

Até o presente escrito, foram vitimados mais de 140 milhões de pessoas, sendo cerca de I4,I milhões somente no Brasil, tornando o país como epicentro pandêmico na América do Sul. O número de óbitos soma-se mais de 3 milhões de pessoas no mundo e mais de 380 mil no Brasil. Singularmente no Ceará, estes números superam 630 mil casos confirmados e 16 mil mortes (BRASIL, 2020)3. Assim, para minimizar o número de infectados, a Organização Mundial da Saúde sugere o isolamento social, bem como evitar aglomerações e intensificar os hábitos de lavagem das mãos corretamente, como medidas paliativas para aviltar a curva de casos e mortes (OMS, 2020).

Neste cenário, o poder público promulgou decretos que promovessem o isolamento social, determinando que apenas os serviços essenciais funcionassem normalmente. Com isso, escolas e universidades tiveram suas aulas presenciais suspensas por tempo indeterminado, passando a utilizarem, com maior frequência, as tecnologias da informação e comunicação na realização das atividades educativas.

\footnotetext{
${ }^{3}$ Dados atualizados até 22 de abril de 2021 .
} 
Jones Baroni Ferreira de Menezes e Francisco Nunes de Sousa Moura

Diante do exposto, as instituições de ensino, o próprio Ministério da Educação e as Secretarias municipais e estaduais de Educação aventaram a utilização da educação à distância $(\mathrm{EaD})$ como opção para a continuidade do planejamento de ensino neste momento emergencial.

A EaD, no Brasil, segundo o Decreto 5622/2005, em seu Art $1^{\circ}$, é tratada como uma modalidade educacional na qual a mediação didático-pedagógica nos processos de ensino e aprendizagem ocorre com a utilização de meios e tecnologias de informação e comunicação, com estudantes e professores desenvolvendo atividades educativas em lugares ou tempos diversos (BRASIL, 2005). Mas, pelas características da modalidade de ensino à distância, podemos comprovar que o ocorrido no Brasil neste momento pandêmico não pode ser considerado uma educação à distância, mas um ensino remoto mediado pelas tecnologias da informação e comunicação (TIC), sobretudo pelo caráter andragógico que esta modalidade traz.

Contudo, é sabido que ainda encontramos dificuldades em desenvolver as possibilidades dos recursos tecnológicos a serem adotados no contexto das atividades cotidianas da rotina educacional, seja na perspectiva infraestrutura, seja na falta de formação adequada dos professores para utilizarem as TIC (MENEZES; MOTA, 20I8; MENEZES; MOURA; SOUSA, 2019). Destarte, o objetivo central desta investigação é compreender a perspectiva de docentes vinculados a um curso de formação de professores sobre o desenrolar das atividades letivas através do ensino remoto.

\section{Desenho metodológico}

A pesquisa apresenta características de um estudo de caso exploratório e descritivo, de abordagem qualitativa. Para Yin (200I), o estudo de caso pode ser utilizado quando é investigado um fenômeno contemporâneo dentro de seu contexto real, podendo este, para Gil (2002), ser exploratório e descritivo pelo fato de possibilitar uma maior familiaridade com o cenário pesquisado, com vistas a torná-lo mais explícito, descrevendo suas principais características. Ademais, Minayo, Deslandes e Gomes (20II) informa que a abordagem qualitativa objetiva aprofundar-se a compreensão dos significados das ações e relações humanas.

Quanto ao cenário das averiguações, realizou-se com docentes vinculados a um curso de licenciatura em Ciências Biológicas de uma universidade pública situada nos Sertões de Crateús, macrorregião do estado do Ceará, distante a cerca de $350 \mathrm{Km}$ da capital Fortaleza, cuja a principal cidade, Crateús, contêm IES públicas e privadas.

O curso ora analisado possui 12 (doze) professores associados. Dois destes docentes estão afastados para cursar pós-graduação e não participaram de atividades acadêmicas nesse período de pandemia. Do restante, 7 (sete) se dispuseram a participar desta pesquisa, cuja idade variou entre 24 e 45 anos, sendo 2 (dois) do sexo masculino e 5 (cinco) do sexo feminino. 
O ensino em tempos de isolamento social: percepção de docentes de um curso de formação de professores

Para a coleta de dados, utilizou-se um questionário eletrônico, produzido pelo Google Formulários ${ }^{4}$ e enviado para o e-mail institucional, durante o mês de maio/2020, último mês do semestre letivo 2019.2, devido a desregulação do calendário acadêmico da instituição.

Este instrumento contou com 30 (trinta) questões objetivas e/ou subjetivas, dividido em três seções: caracterização sócio demográfica; formação e atuação acadêmica; e percepções sobre o ensino remoto em tempos de pandemia. Os dados foram descritos, categorizados e interpretados, conforme preconizado por Bardin (20II).

É precípuo enfatizar que foram atendidos os postulados éticos da Resolução 510/2016 do Conselho Nacional de Saúde (CNS), acompanhado de um Termo de Consentimento Livre e Esclarecido - TCLE, tendo sido disponibilizado na primeira parte do questionário (BRASIL, 20I6). Para preservar a identidade dos participantes, criptografou-se as suas informações e os mesmos foram identificados por códigos (PI, P2, ... P7).

\section{O ensino remoto em tempos de pandemia: o que dizem os professores?}

Inicialmente, consideramos averiguar o aspecto de formação acadêmica dos docentes, destes, 6 (seis) possuem o doutorado como maior titulação e I (um) é mestre. Ademais, 5 (cinco) são licenciados em Ciências Biológicas, I (um) tem graduação em Engenharia de Alimentos e I (um) é bacharel em Biotecnologia. Singularmente à formação para o uso das ferramentas educacionais, apenas 2 (dois) professores sinalizaram possuir algum tipo de formação para uso da TIC no contexto educacional, todavia, todos consideram importante a utilização deste recurso no ensino.

Posteriormente, questionamos aos docentes sobre as ferramentas tecnológicas mais utilizadas nas aulas antes e durante a pandemia, tendo sido atentado que o uso dos slides para projetor multimídia ainda é um forte aliado na prática docente, bem como o e-mail, a rede social Whatsapp ${ }^{\circledR}$ e o uso do Podcast (arquivos de áudio). Vale destacar também que durante a pandemia, uma nova ferramenta emergiu na mediação da aprendizagem, o Google Meet, uma ferramenta disponível no $G$ Suites for Education, possível de utilização por parte dos docentes para realização de encontros virtuais síncronos, inclusive com a possibilidade de realizar apresentações através do espelhamento da tela do computador.

É observado que, apesar de falta de formação especifica para o uso das tecnologias, devido a estarmos inseridos em uma era digital, mesmo antes da COVID-19, os docentes já faziam o uso dos diversos recursos digitais disponíveis. Nada obstante, é importante distinguir que a ampla difusão, por

\footnotetext{
${ }^{4}$ Disponivel em: https://forms.gle/d2mpw8ywi6VNYVEh7.
} 
Jones Baroni Ferreira de Menezes e Francisco Nunes de Sousa Moura exemplo, dos slides e do projetor multimídia, não sinaliza a efetividade destes no contexto educacional, caso seja apenas para virtualizar a aula presencial, sem utilizar a contento o intendo do recurso que possibilite gerar novas competências e habilidades aos discentes (MENEZES, MOURA, RODRIGUES, 2019).

A pandemia, que levou a transição do ensino tradicional para o ensino remoto, ampliou as ferramentas que possibilitam a aula online em tempo real, como o Google Meet que, segundo Kurian (2020), foi uma das primeiras ferramentas disponíveis para a realização de uma web conferência, tendo sua utilização ampliada em 25 vezes na comparação com janeiro deste ano, com um crescimento diário de $60 \%$ de uso nas últimas semanas, tornando satisfatório o uso no processo de ensino e aprendizagem em escolas, conforme Basilaia e Kvavadze (2020).

Complementarmente a este cenário, solicitou-se que os professores avaliassem cada ponto destacado na figura I por meio de uma escala numérica de I a 5, no qual a crescente numérica está diretamente relacionada com a crescente de satisfação quanto ao abordado. Os dados demonstram, em sua maior parte, a insatisfação da formação e uso das tecnologias educacionais nas suas práticas docentes, o que enaltece a insegurança e inabilidade dos professores quanto às TIC, refletindo, inclusive, na percepção deles quanto ao rendimento e aprendizagem dos discentes nesta conjuntura.

Figura I: Satisfação docentes quanto à formação e uso das tecnologias educacionais, 2020.

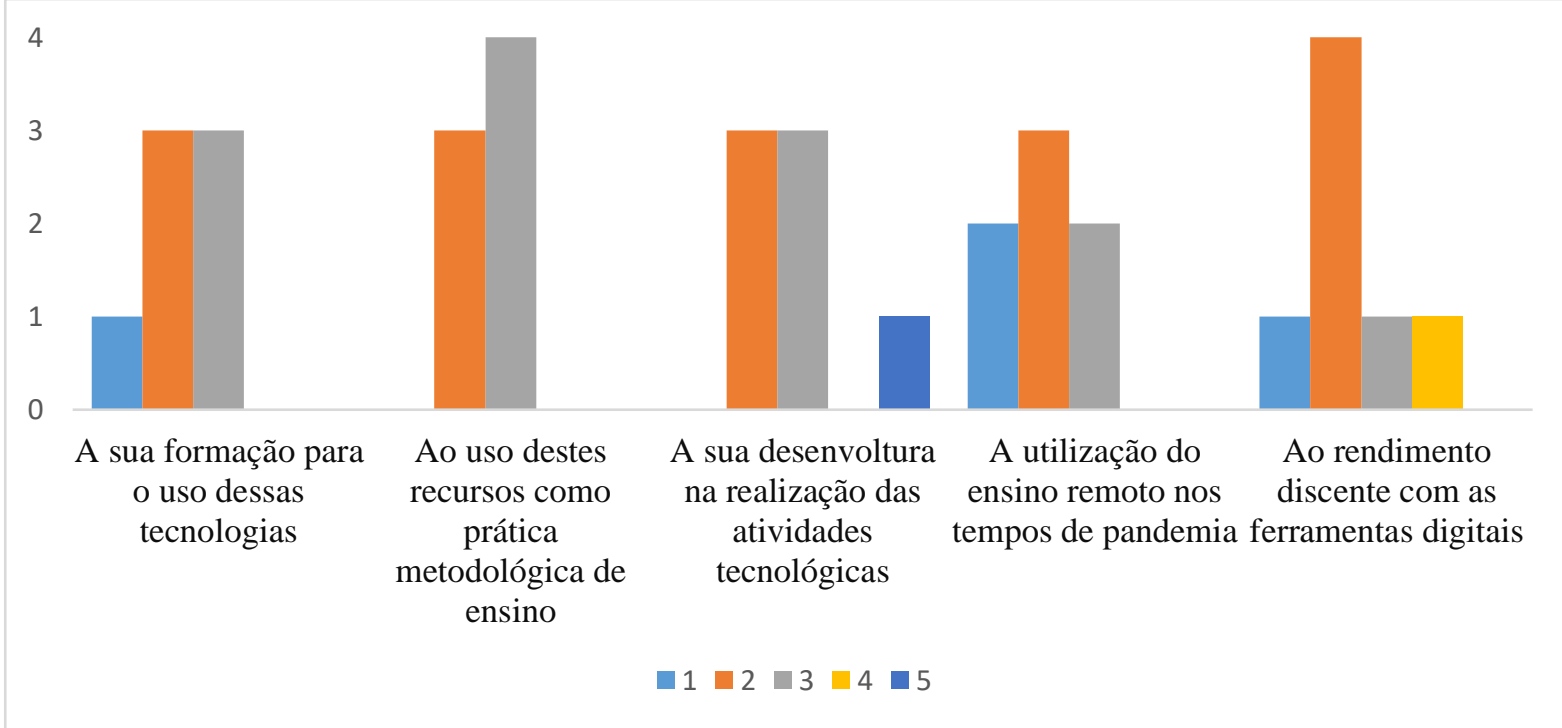

Fonte: Elaborada pelos autores, 2020.

Tal fato é aprofundado quando os docentes afirmam, unanimemente, a falta de apoio/suporte do órgão institucional para o desenvolvimento das suas atividades docentes com o uso das ferramentas tecnológicas, o que sugere a ampliação de políticas públicas e cursos formativos que ampliem a capacitação de docentes, assim como de discentes, preparados para lidar com a tecnologia, 
O ensino em tempos de isolamento social: percepção de docentes de um curso de formação de professores organização, planejamento e acessibilidade tecnológica (XAVIER et al., 2020; SILVA; SOUSA; MENEZES, 2020).

Também indagamos acerca das dificuldades encontradas e benefícios do ensino remoto (figura 2), tendo sido constatando que esta nova forma de ensinar é possibilitada pela diversidade de recursos disponíveis, bem como a flexibilização para reposição/antecipação das aulas. Apesar disso, a dificuldade de acesso à internet e/ou ao computador, tablet e smartphones promove a ausência dos alunos nessas aulas, bem como a falta de retorno deles nas atividades propostas, bem como a dificuldade no planejamento e manuseio das ferramentas são elencados como inconvenientes para o ensino remoto.

Figura 2: Benefícios (a) e Dificuldades (b) encontradas no ensino remoto na perspectiva docente, 2020. (a)

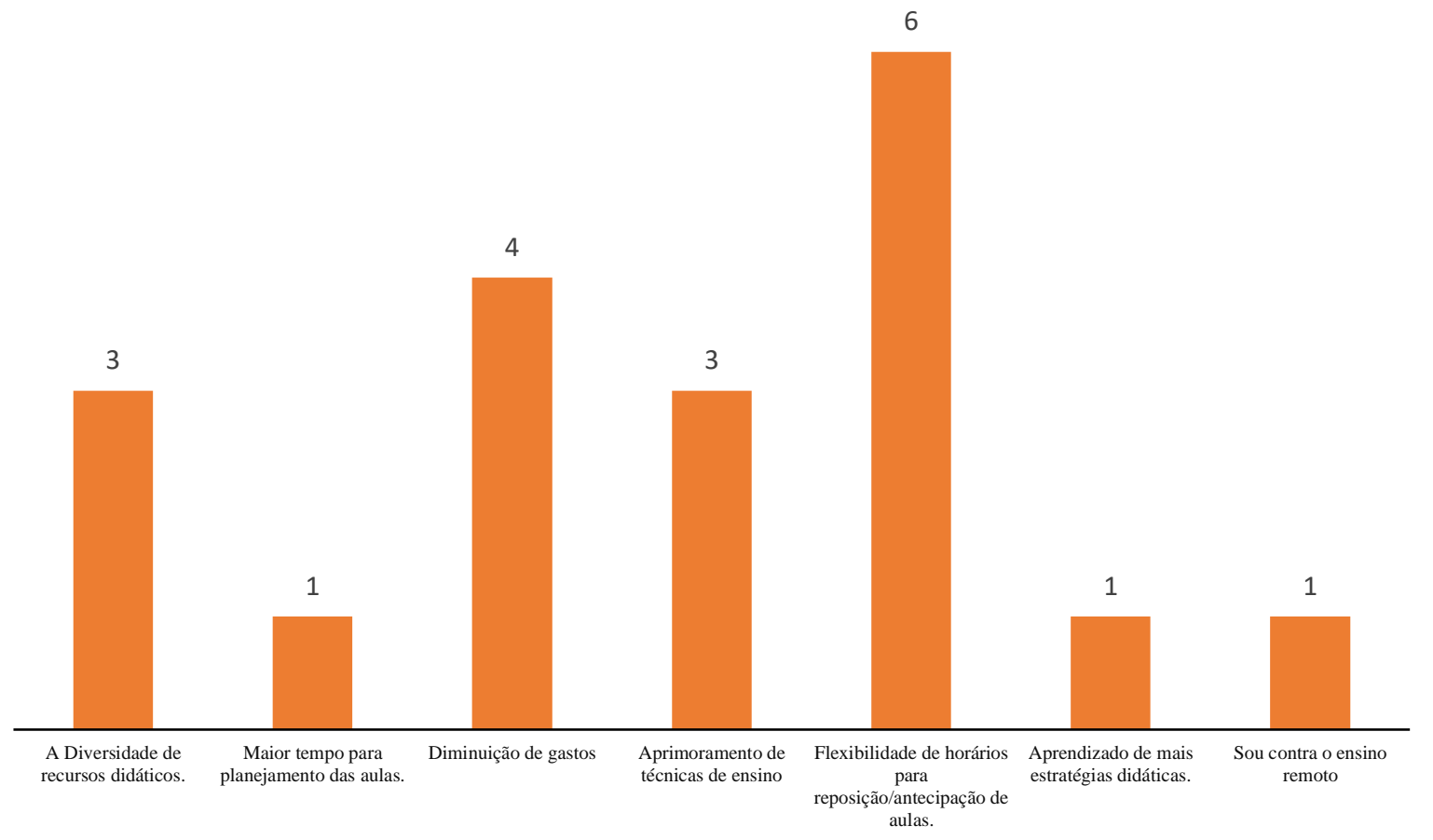

Olhar de professor, Ponta Grossa, v. 24, p. I-10, e-15836.046, 202 I.

Disponível em <https://revistas2.uepg.br/index.php/olhardeprofessor> 
(b)

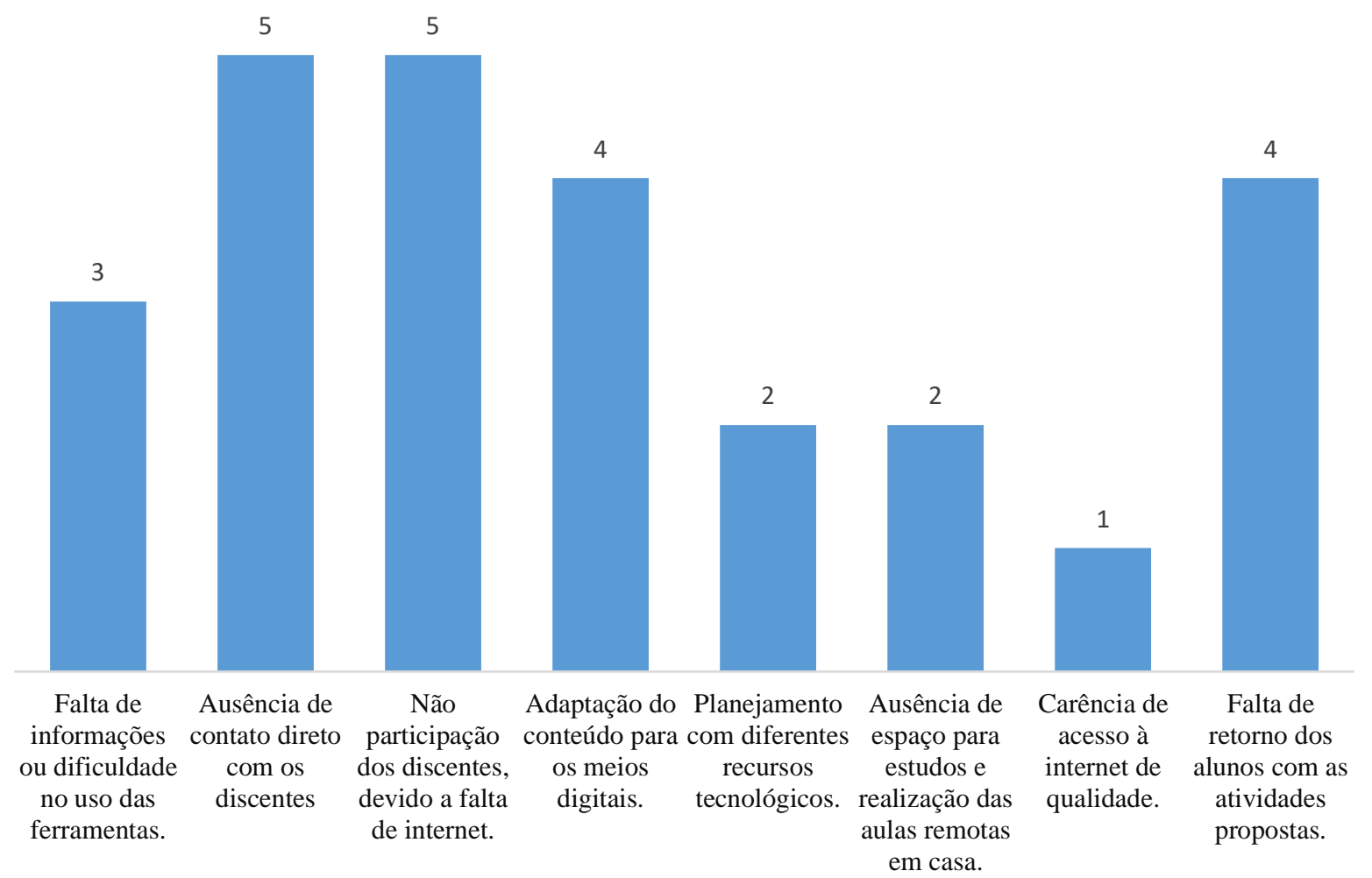

Fonte: Elaborada pelos autores, 2020.

Aprofundando o assunto abordado, questionamos então sobre a utilização do ensino remoto no processo educacional, tendo sido observado que os docentes não o veem como uma forma de ensino principal, mas que pode ser complementar ao ensino presencial, sobretudo nesses tempos de necessário distanciamento entre as pessoas, mas desde que haja formação adequada para este fim, apoio institucional e oferta de infraestrutura adequada a docentes e discentes, conforme registro das falas.

Não. Diversidade de realidade social e econômica (PI).

Sim. Desde que ela seja para complementar as aulas presenciais e não para substituílas (P3).

Sim, condicionada a uma boa formação do professor e uma capacitação do aluno para isso. As tecnologias encurtam distanciamentos sociais, se forem feitas com suporte e de forma adequada (P4).

$\mathrm{Sim}$, mas somente em tempos como este. Pois acredito que os alunos tenham maior acesso as tecnologias ou condições de busca-las (P6). 
O ensino em tempos de isolamento social: percepção de docentes de um curso de formação de professores

Não. $O$ ensino superior vai além de transmitir o conteúdo, mas criar fluxos de pensamentos entre discentes e docente (P7).

Face ao exposto, o avanço do ciberespaço, das tecnologias educacionais e a existência de repositórios de objetos de aprendizagem disponíveis na internet são benéficos no contexto educacional e facilitador da difusão da informação e do conhecimento, do ensino e da aprendizagem (KENSKI, 20I5).

Nesse sentido, é que reafirmamos a necessidade da formação dos professores para atuarem neste contexto, seja na formação inicial (MENEZES; MOTA, 2018) ou continuada (MENEZES, MOURA, SOUSA, 2019). Para além, Paixão, Menezes e Arruda-Filho (2015) anunciam que a efetividade do uso das tecnologias na aprendizagem dar-se diretamente a compreender as características das ferramentas, os objetivos da aprendizagem e as competências e habilidades a serem gerados.

Ainda assim, no Brasil, este cenário é complexo e necessita de políticas públicas e mudanças estruturais no sistema escolar. Segundo dados da Pesquisa Nacional por Amostra de Domicílios Contínua (PNAD Contínua) de 2018, a falta de acesso à internet e posse de telefone móvel celular para uso pessoal ainda é limitada em nosso país, mormente quando referido à região interiorana e rural do Nordeste brasileiro e às famílias de baixa renda (IBGE, 2020), o que dificulta a participação dos alunos nas atividades remotas propostas, assim como amplia a desigualdade educacional.

\section{Considerações finais}

$\mathrm{Na}$ atual pandemia da COVID-19, com o cenário de isolamento social preconizados pelos órgãos governamentais, as ferramentas tecnológicas e os ambientes virtuais de aprendizagem apresentam uma grande possibilidade de aplicação das ferramentas educacionais no ensino, ainda sim, apresentam limitações, especialmente em relação à pouca formação dos docentes para o uso das tecnologias, bem como pela acessibilidade da população interiorana e da zona rural da região Nordeste do Brasil, sítio de realização desta investigação, a uma rede de internet de qualidade e de equipamentos como computador, tablets ou smartphones.

Portanto, o advento de situações que exijam o distanciamento social, como o presenciado neste momento, afeta a sociedade como um todo. Nos sistemas educacionais, singularmente, aflora a necessidade dos avanços que se necessita ter no quesito formação docente, infraestrutura das escolas/universidades e suporte institucional. Ademais, amplifica e exprime a desigualdade social e econômica que é imperativa no país, necessitando de políticas públicas para que estas sejam minimizadas e, para assim, termos um sistema de maior equidade.

Olhar de professor, Ponta Grossa, v. 24, p. I-10, e-15836.046, 202 I.

Disponível em <https://revistas2.uepg.br/index.php/olhardeprofessor> 


\section{Referências}

BARDIN, L. Análise de conteúdo. São Paulo: Edições 70, 2011.

BASILAIA, G.; KVAVADZE, D. Transition to online education in schools during a SARS-CoV-2 coronavirus (COVID-19) pandemic in Georgia. Pedagogical Research, Londres, v. 5, n. 4, p. I-9, 2020.

BRASIL, Conselho Nacional de Saúde. Resolução n 5 I 0, de 07 de abril de 2016. Normas aplicáveis a pesquisas em Ciências Humanas e Sociais cujos procedimentos metodológicos envolvam a utilização de dados diretamente obtidos com os participantes ou de informações identificáveis ou que possam acarretar riscos maiores do que os existentes na vida cotidiana. Diário Oficial Da União, Brasilia, Edição 98, seção I, p. 44, 2016.

BRASIL, Ministério da Educação. Decreto $n^{\circ}$ 5622, de 19 de dezembro de 2005. Regulamenta o art. 80 da Lei $n^{\circ}$ 9.394, de 20 de dezembro de 1996, que estabelece as diretrizes e bases da educação nacional. Diário Oficial da União, Brasília - Seção I, 2005.

BRASIL. Ministério da Saúde. Painel Coronavírus - COVID 19. 2020. Disponível em: $<$ https://covid.saude.gov.br/> Acesso em: 8 ago. 2020.

GIL, A. C. Como elaborar projetos de pesquisa. 4. ed. São Paulo: Atlas, 2002.

IBGE - Instituto Brasileiro de Geografia e Estatística. Pesquisa Nacional por Amostra de Domicílios Contínua - PNAD Contínua 2016 - 2018. 2020. Disponível em: < https://biblioteca.ibge.gov.br/visualizacao/livros/liv101705_informativo.pdf> Acesso em: 6 jun. 2020.

KENSKI, V. M. Educação e internet no Brasil. Cad Adenauer, Berlim, v. 16, n. 3, p. I33-I50, 2015.

KHAN, S. et al. Emergence of a novel coronavirus, severe acute respiratory syndrome coronavirus 2: biology and therapeutic options. Journal of clinical microbiology, Washington, v. 58, n. 5 , e00187-20, p. I-II, 2020.

KURIAN, T. Como Google Cloud está ajudando durante a pandemia de COVID-I9. Disponível em: <https://brasil.googleblog.com/2020/04/covid I9-googlecloud-apoio-empresasgovernos.html>. Acesso em: 6 jun. 2020.

MENEZES, J. B. F.; MOTA, F. D. L. O uso das tecnologias educacionais durante o exercício da monitoria acadêmica em um curso de ciências biológicas. Revista Brasileira de Iniciação Científica, São Paulo, v. 6, n. I, p. 96-108, 2018.

MENEZES, J. B. F.; MOURA, F. N. S.; SOUSA, S. A. Utilização das tecnologias digitais por docentes vinculados à cursos de licenciatura ofertados no município de Crateús-CE. Ciência \&

Desenvolvimento-Revista Eletrônica da FAINOR, Vitória da Conquista, v. 12, n. I, p. III-I28, 2019.

DE SOUZA MINAYO, Maria Cecília; DESLANDES, Suely Ferreira; GOMES, Romeu. Pesquisa social: teoria, método e criatividade. Editora Vozes Limitada, $201 \mathrm{I}$. 
MOURA, F. N. S.; RODRIGUES, C. M. C.; MENEZES, J. B. F. Tecnologias digitais educacional: tessituras da prática docente. Ensino em Foco, Salvador, v. 2, n. 5, p. 72-86, 2019.

OMS - ORGANIZAÇÃO MUNDIAL DA SAÚDE. Coronavirus disease (COVID- 19) situation report-1 02. 2020. Disponível em: <https://www.who.int/docs/default-source/coronaviruse/situationreports/2020050 I-covid-I9-sitrep.pdf?sfvrsn=742f4al8_2>. Acesso em: 27 maio 2020.

PAIXÃO, G. C.; MENEZES, J. B. F.; ARRUDA-FILHO, J. N. Escolha de ferramentas multimídias para atividades a distância a partir de características pedagógicas e tecnológicas. In: $6^{\circ}$ SEMINÁRIO NACIONAL DO EDAPECI, 20I5, Maceió. Anais [...] Maceió: EDaPECI, 20I5, p. 34I-35I.

PUELLES, V. G. et al. Multiorgan and renal tropism of SARS-CoV-2. New England Journal of Medicine, Massachusetts, v. 6, n. 383, p. 590-592, 2020.

SILVA, Ana Carolina Oliveira; DE ARAÚJO SOUSA, Shirliane; DE MENEZES, Jones Baroni Ferreira. O ensino remoto na percepção discente: desafios e benefícios. Dialogia, São Paulo, n. 36, p. 2983I5, 2020.

XAVIER, T. B. et al. Utilização de recursos web na educação em odontologia durante pandemia COVID-19. Brazilian Journal of Health Review, São José dos Pinhais, v. 3, n. 3, p. 4989-5000, 2020.

YIN, R. K. Estudo de caso: planejamento e métodos. 2. ed. Porto Alegre: Bookman, 200I.

Recebido em: 06 de junho de 2020.

Versão corrigida recebida em: 22 de julho de 2020.

Aceito em: II de setembro de 2020.

Publicado online em: 08 de maio de 2021 .

Olhar de professor, Ponta Grossa, v. 24, p. I-10, e-15836.046, 202 I.

Disponível em <https://revistas2.uepg.br/index.php/olhardeprofessor> 